\title{
EFEK PEKERJAAN RUMAH TANGGA DALAM PENCEGAHAN PENURUNAN FUNGSI KOGNITIF PADA LANSIA PEREMPUAN BERPENDIDIKAN RENDAH
}

\author{
EFFECTS OF HOUSEWORK IN PREVENTION OF COGNITIVE DECLINE IN ELDERLY \\ WOMEN WITH LOW EDUCATION
}

\author{
Christina Permata Shalim, * Julia Rahadian, * Yuda Turana*
}

\begin{abstract}
Introduction: Physical activities have a role in preventing or slowing down cognitive decline. In Indonesia, physical activity in the elderly women is dominated with house work chores.

Aims: This study was aimed to determine the relationship between house chores with cognitive function in elderly women.

Methods: A cross sectional analytic descriptive of 65 women aged 60 years and over with highest education level of junior high school that live in Kalianyar, West Jakarta, between October to November 2014. Physical activity was measured by questionnaire about nine housework activities that Indonesian women usually do and cognitive function was assessed by Mini-Mental State Examination (MMSE).

Results: In this study of 65 subjects with a mean age of 64.31 years and low education level, there was a significant relationship between the higher amount of physical activity and better cognitive level. The types of physical activity that had a significant relationship with better cognitive function was cooking, grocery shopping, and washing dishes, with the frequency of cooking and grocery shopping had a significant relationship.
\end{abstract}

Discussion: Cooking and grocery shopping activity have a relationship with better cognitive function.

Keywords: Cognitive function, daily physical activity, elderly, house chores

\begin{abstract}
ABSTRAK
Pendahuluan: Aktivitas fisik dianggap memiliki peran dalam pencegahan atau perlambatan penurunan fungsi kognitif. Di Indonesia, aktivitas fisik pada lansia perempuan didominasi dengan pekerjaan rumah tangga.

Tujuan: Mengetahui hubungan aktivitas fisik pekerjaan rumah tangga terhadap fungsi kognitif pada lansia perempuan.

Metode: Penelitian deskriptif analitik potong lintang terhadap lansia ( $>60$ tahun) perempuan yang mengenyam pendidikan akhir paling tinggi tamat SMP dan tinggal di Kelurahan Kalianyar, Jakarta Barat, pada bulan Oktober-November 2014. Aktivitas fisik diukur menggunakan kuesioner sembilan aktivitas pekerjaan rumah tangga yang dilakukan lansia perempuan Indonesia dan penilaian fungsi kognitif menggunakan Mini-Mental State Examination (MMSE).

Hasil: Pada penelitian terhadap 65 subjek dengan rerata usia 64,31 tahun berpendidikan rendah, terdapat hubungan bermakna antara jumlah aktivitas fisik yang dilakukan dengan fungsi kognitif yang lebih baik. Adapun jenis aktivitas fisik yang memiliki hubungan bermakna dengan fungsi kognitif yang lebih baik adalah memasak, berbelanja, dan mencuci piring, terutama frekuensi memasak dan berbelanja yang lebih sering memiliki hubungan secara bermakna.
\end{abstract}

Diskusi: Aktivitas memasak dan berbelanja berhubungan dengan fungsi kognitif yang lebih baik.

Kata kunci: Aktivitas fisik sehari-hari, fungsi kognitif, lansia, pekerjaan rumah tangga

*FK Universitas Katolik Atma Jaya, Jakarta. Korespondensi: yudaturana@yahoo.com.

\section{PENDAHULUAN}

Seiring bertambahnya angka harapan hidup, jumlah lanjut usia (lansia) terus meningkat. ${ }^{1}$ Salah satu penyakit degeneratif yang banyak dialami para lansia adalah gangguan fungsi kognitif. ${ }^{2}$ Selain merupakan salah satu penyebab utama disabilitas pada orangtua, penurunan fungsi kognitif ini juga menimbulkan dampak sosial dan ekonomi yang signifikan dengan besarnya biaya kesehatan yang perlu dikeluarkan. ${ }^{3}$ Salah satu faktor yang dianggap berpengaruh terhadap pencegahan atau perlambatan penurunan fungsi kognitif adalah aktivitas fisik. ${ }^{4-5}$

Beberapa penelitian berfokus terhadap aktivitas fisik berupa olahraga dengan intensitas sedang dan kuat, penelitian lain menunjukkan pengaruh aktivitas fisik total dengan mengikutsertakan aktivitas bukan olahraga dalam pengukurannya. ${ }^{6-7}$ Namun penelitianpenelitian tersebut tidak berfokus pada hubungan 
aktivitas pekerjaan rumah tangga terhadap fungsi kognitif. ${ }^{8-9}$ Di Indonesia, aktivitas fisik pada lansia perempuan didominasi dengan pekerjaan rumah tangga, karena faktor sosiokultural yang menempatkan perempuan sebagai pengurus rumah tangga.

\section{TUJUAN}

Mengetahui hubungan aktivitas fisik berupa pekerjaan rumah tangga dengan fungsi kognitif pada lansia perempuan.

\section{METODE}

Penelitian ini merupakan studi potong lintang deskriptif analitik terhadap lansia (usia $\geq 60$ tahun) perempuan pada bulan Oktober-November 2014. Seluruh subjek merupakan lansia binaan Fakultas Kedokteran Universitas Katolik (FK Unika) Atma Jaya, Jakarta yang bertempat tinggal di Kelurahan Kalianyar, Jakarta Barat. Kriteria inklusi adalah subjek berpendidikan rendah, tidak memiliki hambatan untuk diwawancara, dan bersedia menjadi sampel penelitian. Penelitian ini telah disetujui oleh Komite Etik Fakultas Kedokteran Universitas Katolik Atma Jaya, Jakarta dan semua subjek yang telibat telah memberikan persetujuan tertulis.

Pengukuran aktivitas fisik pada penelitian ini menggunakan kuesioner dengan berfokus pada aktivitas fisik pekerjaan rumah tangga yang dilakukan dalam satu minggu terakhir. Terdapat 9 pekerjaan rumah tangga yang ditanyakan beserta frekuensinya, mulai dari yang skala ringan sampai sedang. Kisaran berdasarkan Metabolic Equivalent of Task (MET) antara 1,8-3,8 METs yang biasa dilakukan seharihari, yaitu menggendong anak kecil (3 METs), merawat anak kecil (2-3 METs), memasak (2,6-3,5 METs), berbelanja (2,3 METs), menyapu (3,8 METs), mengepel (3,5 METs), menyikat lantai/kamar mandi (3,5 METs), menyetrika (1,8 METs), dan mencuci piring $(1,8-2,6 \mathrm{METs}) .{ }^{10}$

Banyaknya aktivitas fisik dalam sehari dibagi menjadi $<5$ dan $\geq 5$ aktivitas fisik. Adapun frekuensi tiap aktivitas fisik yang dilakukan dalam satu minggu dibagi menjadi 1 hari, beberapa hari (4-6 hari), dan setiap hari (7 hari). Pengukuran fungsi kognitif menggunakan Mini-Mental State Examination (MMSE). Analisis statistik menggunakan SPSS versi 20.0 dengan nilai kemaknaan $\mathrm{p}<0,05$.

\section{HASIL}

Didapatkan 65 subjek lansia perempuan (Tabel 1) dengan rerata usia 64,31 tahun yang mayoritas melakukan $\geq 5$ aktivitas fisik $(67,7 \%)$ dan mengalami gangguan fungsi kognitif (52,3\%).

Tabel 1. Jumlah Aktivitas Fisik dan Fungsi Kognitif $(n=65)$

\begin{tabular}{ll}
\hline \multicolumn{1}{c}{ Karakteristik } & n (\%) \\
\hline Jumlah aktivitas fisik & \\
- Aktivitas $<5$ & $21(32,3)$ \\
- Aktivitas $\geq 5$ & $44(67,7)$ \\
Fungsi Kognitif & \\
- Terganggu & $34(52,3)$ \\
- Normal & $31(47,7)$ \\
\hline
\end{tabular}

Aktivitas fisik yang paling banyak dilakukan subjek (Tabel 2) adalah mencuci piring (83\%) dan menyapu $(80 \%)$, sedangkan kegiatan yang paling jarang dilakukan adalah menggendong dan merawat anak kecil (37\% dan 31\%).

Tabel 2. Aktivitas Fisik yang Dilakukan Subjek $(n=65)$

\begin{tabular}{lcc}
\hline \multicolumn{1}{c}{ Aktivitas Fisik } & $\begin{array}{c}\text { Ya } \\
\text { n (\%) }\end{array}$ & $\begin{array}{c}\text { Tidak } \\
\text { n (\%) }\end{array}$ \\
\hline Menggendong anak kecil & $24(37)$ & $41(63)$ \\
Merawat anak kecil & $20(31)$ & $45(69)$ \\
Memasak & $51(78)$ & $14(22)$ \\
Berbelanja & $38(58)$ & $27(42)$ \\
Menyapu & $52(80)$ & $13(20)$ \\
Mengepel & $39(60)$ & $26(40)$ \\
Menyikat lantai/kamar mandi & $43(66)$ & $22(34)$ \\
Menyetrika & $30(46)$ & $35(54)$ \\
Mencuci piring & $54(83)$ & $11(17)$ \\
\hline
\end{tabular}

Tabel 3 menunjukkan bahwa melakukan 5 atau lebih aktivitas fisik berhubungan dengan fungsi kognitif yang lebih baik ( $\mathrm{p}=0,008 ; \mathrm{RO}=4,622)$, yaitu memasak, berbelanja, dan mencuci piring (Tabel 4). Kemudian dilakukan analisis multivariat antara frekuensi melakukan ketiga kegiatan tersebut dengan gangguan fungsi kognitif (Tabel 5). Didapatkan subjek yang sering melakukan kegiatan memasak dan berbelanja akan cenderung mempunyai fungsi kognitif yang lebih baik secara bermakna dibandingkan dengan yang tidak memasak dan berbelanja $(p=0,014$ dan $\mathrm{p}=0,006$ ). 
Tabel 3. Hubungan Jumlah Aktivitas dengan Fungsi Kognitif ( $n=65)$

\begin{tabular}{|c|c|c|c|c|}
\hline \multirow{3}{*}{$\begin{array}{c}\text { Jumlah } \\
\text { Aktivitas } \\
\text { Fisik }\end{array}$} & \multicolumn{2}{|c|}{ Fungsi Kognitif } & \multirow{3}{*}{$\mathbf{p}^{*}$} & \multirow{3}{*}{ RO } \\
\hline & $\begin{array}{c}\text { Terganggu } \\
(n=34)\end{array}$ & $\begin{array}{c}\text { Normal } \\
(n=31)\end{array}$ & & \\
\hline & n (\%) & n (\%) & & \\
\hline - $<5$ & $16(24,6)$ & $5(7,7)$ & 0,008 & 4,622 \\
\hline - $\geq 5$ & $18(27,7)$ & $26(40)$ & & \\
\hline
\end{tabular}

*Uji Chi-square, RO: rasio Odds.

\section{PEMBAHASAN}

Fungsi kognitif pada lansia dipengaruhi oleh beberapa faktor, antara lain aktivitas fisik dan perbedaan intensitas tiap aktivitas. Penelitian ini hanya melibatkan lansia perempuan karena aktivitas fisik yang menjadi dasar pengukuran adalah pekerjaan rumah tangga yang lebih banyak dilakukan oleh perempuan. Tingkat pendidikan yang diikutsertakan pendidikan rendah, berdasarkan suatu tinjauan sistematik bahwa orang berpendidikan rendah lebih berisiko menderita demensia, sehingga pengaruh aktivitas fisik terhadap fungsi kognitif diharapkan lebih mudah terlihat. ${ }^{11}$

Hasil penelitian ini menunjukkan hubungan bermakna antara aktivitas fisik dengan fungsi kognitif, sesuai dengan Blondell dkk bahwa aktivitas fisik berhubungan dengan menurunnya risiko terkena demensia sampai $18 \%{ }^{12}$ Penelitian Jonasson dkk juga menunjukkan bahwa orang tua yang diberi perlakuan berupa latihan fisik aerobik selama enam bulan memiliki peningkatan kognitif yang lebih baik. ${ }^{13}$

Terdapat beberapa hipotesis mengenai mekanisme aktivitas fisik dalam mempertahankan fungsi kognitif, seperti volume substansia grisea yang lebih besar, pelepasan brain-derived neurotrophic factor (BDNF) selama melakukan aktivitas fisik, serta pengaruhnya terhadap fungsi kardiovaskular dan fungsi endotel. ${ }^{14-16}$

Pada penelitian ini, aktivitas fisik yang diukur adalah aktivitas fisik sehari-hari berupa pekerjaan rumah tangga dengan intensitas ringan sampai sedang, sedangkan penelitian lain lebih menekankan aktivitas fisik berupa olahraga dengan intensitas sedang sampai berat. Terdapat penelitian mengenai aktivitas fisik non-olahraga, namun tidak berfokus pada pekerjaan rumah tangga terhadap fungsi kognitif..$^{8-9}$ Penelitian ini juga memiliki subjek yang cukup homogen dengan semua subjek lansia perempuan berpendidikan rendah yang sehari-hari lebih banyak melakukan kegiatan di rumah.

Suatu tinjauan sistemik menyimpulkan bahwa hubungan aktivitas fisik intensitas rendah, memberikan keuntungan terhadap fisik maupun fungsi kognitif pada lansia, terutama perempuan. ${ }^{17}$ Adapun Murphy dkk menyimpulkan bahwa melakukan pekerjaan rumah tangga berhubungan secara negatif dengan proporsionalitas tubuh berdasarkan inverted body mass index (iBMI), sehingga tetap membutuhkan aktivitas fisik lain untuk mencapai tingkat yang direkomendasikan bagi kesehatan. ${ }^{18}$ Perbedaan hasil ini mungkin berhubungan dengan beberapa hasil penelitian yang menunjukkan perbedaan intensitas aktivitas fisik yang bermanfaat bagi fungsi kognitif dengan yang dibutuhkan untuk meningkatkan kebugaran kardiovaskular. ${ }^{19}$

Penelitian ini juga mendapatkan hasil bahwa melakukan kegiatan memasak, berbelanja, dan mencuci piring memiliki hubungan bermakna dengan fungsi kognitif, dengan hanya frekuensi memasak dan berbelanja yang juga berhubungan secara bermakna. Selain dari segi aktivitas fisiknya, memasak, berbelanja, dan mencuci piring mungkin memiliki hubungan yang bermakna terhadap fungsi kognitif didasari juga oleh aspek kognitif yang terlibat dalam proses melakukannya. Memasak dikategorikan sebagai aktivitas kreatif, yaitu aktivitas yang melibatkan proses intelektual dalam mengidentifikasi masalah, memilih strategi pemecahan masalah yang tepat, dan menggunakan pengetahuan untuk memecahkan masalah tersebut. Aktivitas kreatif ini dianggap memiliki hubungan yang bermakna dengan fungsi kognitif. ${ }^{20}$ Terapi kelompok yang terdiri dari memasak dan aktivitas fisik pada orang tua dengan demensia ringan di Jepang juga memberikan pengaruh yang positif terhadap aspek kognitif dan psikologis pasien. ${ }^{21}$

Untuk kegiatan berbelanja, Okahashi dkk menyatakan bahwa untuk melakukannya, subjek menggunakan 'atensi selektif' ketika memilih toko, tujuan dan barang yang tepat, serta dibutuhkan juga 'memori' untuk mengingat daftar barang yang akan dibeli. ${ }^{22}$ Memasak dan berbelanja juga termasuk 
Tabel 4. Hubungan Jenis Aktivitas dengan Fungsi Kognitif $(n=65)$

\begin{tabular}{|c|c|c|c|c|}
\hline \multirow{3}{*}{ Aktivitas } & \multicolumn{2}{|c|}{ Fungsi Kognitif } & \multirow{3}{*}{$\mathbf{p}^{*}$} & \multirow{3}{*}{$\mathbf{R O}$} \\
\hline & Terganggu $(n=34)$ & Normal $(n=31)$ & & \\
\hline & n (\%) & n (\%) & & \\
\hline \multicolumn{5}{|l|}{ Menggendong anak kecil } \\
\hline - Ya & $12(18,5)$ & $12(18,5)$ & & \\
\hline - Tidak & $22(33,8)$ & $19(29,2)$ & 0,776 & 1,158 \\
\hline \multicolumn{5}{|l|}{ Merawat anak kecil } \\
\hline - Ya & $8(12,3)$ & $12(18,5)$ & 0,185 & 2,053 \\
\hline - Tidak & $26(40)$ & $19(29,2)$ & & \\
\hline \multicolumn{5}{|l|}{ Memasak } \\
\hline - Ya & $22(33,8)$ & $29(44,6)$ & 0,005 & 7,909 \\
\hline - Tidak & $12(18,5)$ & $2(3,1)$ & & \\
\hline \multicolumn{5}{|l|}{ Berbelanja } \\
\hline - $\mathrm{Ya}$ & $15(23,1)$ & $23(35,4)$ & 0,014 & 3,642 \\
\hline - Tidak & $19(29,2)$ & $8(12,3)$ & & \\
\hline \multicolumn{5}{|l|}{ Menyapu } \\
\hline - Ya & $25(38,5)$ & $27(41,5)$ & 0,172 & 2,430 \\
\hline - Tidak & $9(13,8)$ & $4(6,2)$ & & \\
\hline \multicolumn{5}{|l|}{ Mengepel } \\
\hline - Ya & $18(27,7)$ & $21(32,3)$ & 0,224 & 1,867 \\
\hline - Tidak & $16(24,6)$ & $10(15,4)$ & & \\
\hline \multicolumn{5}{|c|}{ Menyikat lantai/kamar mandi } \\
\hline - Ya & $21(32,3)$ & $22(33,9)$ & & \\
\hline - Tidak & $13(20)$ & $9(13,8)$ & 0,434 & 1,513 \\
\hline \multicolumn{5}{|l|}{ Menyetrika } \\
\hline - Ya & $12(18,5)$ & $18(27,7)$ & 0,066 & 2,538 \\
\hline - Tidak & $22(33,8)$ & $13(20)$ & & \\
\hline \multicolumn{5}{|l|}{ Mencuci piring } \\
\hline - $\mathrm{Ya}$ & $25(38,5)$ & $29(44,6)$ & 0,032 & 5,220 \\
\hline - Tidak & $9(13,8)$ & $2(3,1)$ & & \\
\hline
\end{tabular}

*Uji Chi-square, RO: rasio Odds.

Tabel 5. Hubungan Frekuensi Aktivitas dengan Fungsi Kognitif

\begin{tabular}{lcc}
\hline \multicolumn{1}{c}{ Aktivitas } & \multicolumn{2}{c}{ Fungsi Kognitif } \\
\cline { 2 - 3 } & Terganggu (n=34) & Normal (n=31) \\
\cline { 2 - 3 } Memasak & $\mathbf{n}(\mathbf{\%})$ & $\mathbf{n}(\mathbf{\%})$ \\
- Tidak melakukan & $12(18,5)$ & $2(3,1)$ \\
- 1 hari + beberapa hari & $9(13,8)$ & $9(13,8)$ \\
- Setiap hari & $13(20)$ & $20(30,8)$ \\
Berbelanja & & \\
- Tidak melakukan & $19(29,2)$ & $8(12,3)$ \\
- 1 hari + beberapa hari & $11(16,9)$ & $9(13,9)$ \\
- Setiap hari & $4(6,2)$ & $14(21,5)$ \\
Mencuci piring & & \\
- Tidak melakukan & $9(13,8)$ & $2(3,1)$ \\
- 1 hari + beberapa hari & $5(7,7)$ & $4(6,1)$ \\
- Setiap hari & $20(30,8)$ & $25(38,5)$ \\
\hline
\end{tabular}

*Uji Chi-square. 
instumental activity of daily living (IADL), yaitu aktivitas sehari-hari kompleks yang dianggap berhubungan erat dengan fungsi kognitif dan dapat menjadi prediktor penurunan fungsi kognitif.. 23 Gangguan fungsi eksekutif merupakan kontributor penting terhadap penurunan kemampuan seseorang melakukan IADL dan dalam beberapa studi dianggap sebagai aspek kognitif yang paling konsisten berhubungan dengan kemampuan melakukan aktivitas sehari-hari. ${ }^{24}$

Aktivitas mencuci piring, seperti kegiatan memasak dan berbelanja, juga termasuk IADL yang dianggap berhubungan erat dengan fungsi kognitif. ${ }^{23}$ Tidak seperti kegiatan memasak dan berbelanja, tidak ditemukan tulisan mengenai hubungan aktivitas mencuci piring secara khusus dengan fungsi kognitif. Aktivitas ini juga sebenarnya tidak banyak berbeda dengan aktivitas fisik lain yang juga ditanyakan dalam penelitian ini, tetapi tidak memiliki hubungan yang bermakna dengan fungsi kognitif. Beberapa aspek kognitif memang dibutuhkan dalam pengerjaannya, tetapi tidak sebanyak yang dibutuhkan untuk melakukan kegiatan memasak dan berbelanja. Mencuci piring sendiri merupakan kegiatan yang paling banyak dilakukan subjek $(83 \%)$ penelitian ini. Meskipun belum diketahui apakah memang ada faktor khusus lain yang memengaruhi hubungannya dengan fungsi kognitif, tetapi kemungkinan adanya bias karena kebanyakan dari subjek memang melakukan aktivitas ini.

Penelitian mengenai hubungan jenis pekerjaan rumah tangga secara spesifik dengan fungsi kognitif sendiri masih sangat terbatas. Wen dkk mempelajari hubungan antara empat jenis pekerjaan rumah tangga (merawat anak kecil, merawat orang tua, berbelanja dan memasak, serta mencuci pakaian dan membersihkan rumah) terhadap keluhan kesehatan selama dua minggu terakhir pada orang tua yang telah pensiun. Hasil penelitian tersebut menyatakan bahwa hampir tidak terdapat hubungan yang signifikan antara empat jenis pekerjaan rumah tangga dengan keluhan kesehatan, kecuali mencuci pakaian \& membersihkan rumah yang memiliki efek negatif pada perempuan. Dijelaskan bahwa mungkin yang memengaruhi efek negatif adalah karena kedua kegiatan tersebut merupakan kegiatan yang hampir tanpa komunikasi dengan orang lain dan membosankan, sehingga meskipun memiliki manfaat bagi kesehatan, tetapi faktor psikologis dan sosial dari pekerjaan tersebut dapat memengaruhi hubungannya dengan kesehatan secara keseluruhan. ${ }^{25}$

Penelitian ini juga tidak terlepas dari beberapa keterbatasan. Desain penelitian yang bersifat potong lintang menyebabkan kesulitan untuk melihat hubungan sebab akibat antara variabel-variabel yang diuji. Pengukuran aktivitas fisik yang menanyakan sembilan jenis aktivitas fisik dengan tujuan agar hanya fokus pada aktivitas fisik berupa pekerjaan rumah tangga juga mungkin kurang dapat merefleksikan keaktifan fisik sesungguhnya dari subjek. Oleh karena itu diperlukan penelitian selanjutnya untuk mendata seluruh aktivitas pekerjaan rumah tangga dalam jangka waktu tertentu agar pengukuran menjadi semakin akurat.

\section{KESIMPULAN}

Terdapat hubungan antara jumlah aktivitas fisik pekerjaan rumah tangga yang dilakukan perempuan lanjut usia dengan fungsi kognitif, terutama frekuensi memasak dan berbelanja berhubungan dengan fungsi kognitif yang lebih baik.

\section{DAFTAR PUSTAKA}

1. He W, Goodkind D, Kowal P. An aging world: 2015. International population report. Washington; US Cencus Bureau: US Government Publishing Office. 2016;16(1):95.

2. Murman DL. The Impact of Age on Cognition. Semin Hear. 2015;36(3):111-21.

3. Hurd MD, Martorell P, Delavande A, Mullen KJ, Langa KM. Monetary costs of dementia in the United States. N Engl J Med. 2013;368(14):1326-34.

4. World Health Organization. Dementia. Facsheet Media Centre. 2017.

5. Gary RA, Brunn K. Aerobic exercise as an adjunct therapy for improving cognitive function in heart failure. Cardiol Res Pract. 2014;2014:e157508.

6. Kirk-Sanchez NJ, McGough EL. Physical exercise and cognitive performance in the elderly: current perspectives. Clin Interv Agin. 2013;9:51-62.

7. Voss MW, Heo S, Prakash RS, Erickson KI, Alves $\mathrm{H}$, Chaddock L, dkk. The influence of aerobic fitness on cerebral white matter integrity and cognitive function in older adults: results of a one-year exercise intervention. Hum Brain Mapp. 2013;34(11):297285. 
8. Carvalho A, Rea IM, Parimon T, Cusack BJ. Physical activity and cognitive function in individuals over 60 years of age: a systematic review. Clin Interv Aging. 2014;9:661-82.

9. Buchman AS, Boyle PA, Yu L, Shah RC, Wilson RS, Bennett DA. Total daily physical activity and the risk of $\mathrm{AD}$ and cognitive decline in older adults. Neurology. 2012;78(17):1323-9.

10. Ainsworth BE, Haskell WL, Herrmann SD, Meckes $\mathrm{N}$, Bassett DR, Tudor-Locke C, dkk. Compendium of physical activities: a second update of codes and MET values. Med Sci Sports Exerc. 2011;43(8):1575-81.

11. Meng X, D'Arcy C. Education and dementia in the context of the cognitive reserve hypothesis: a systematic review with meta-analyses and qualitative analyses. PLoS One. 2012;7(6):e38268.

12. Blondell SJ, Hammersley-Mather R, Veerman JL. Does physical activity prevent cognitive decline and dementia?: a systematic review and metaanalysis of longitudinal studies. BMC Public Health. 2014;14(1):510.

13. Jonasson LS, Nyberg L, Kramer AF, Lundquist A, Riklund K, Boraxbekk C-J. Aerobic exercise intervention, cognitive performance, and brain structure: results from the Physical Influences on Brain in Aging (PHIBRA) Study. Front Aging Neurosci. 2017;8:336.

14. Erickson KI, Leckie RL, Weinstein AM. Physical activity, fitness, and gray matter volume. Neurobiol Aging. 2014;35(Supl 2):S20-8.

15. Piepmeier AT, Etnier JL. Brain-derived neurotrophic factor (BDNF) as a potential mechanism of the effects of acute exercise on cognitive performance. J Sport Heal Sci. 2015;4(1):14-23.

16. Schmidt W, Endres M, Dimeo F, Jungehulsing GJ. Train the vessel, gain the brain: physical activity and vessel function and the impact on stroke prevention and outcome in cerebrovascular disease. Cerebrovasc Dis. 2013;35(4):303-12.
17. Tse ACY, Wong TWL, Lee PH. Effect of lowintensity exercise on physical and cognitive health in older adults: a systematic review. Sport Med Open. 2015;1(1):37.

18. Murphy MH, Donnelly P, Breslin G, Shibli S, Nevill AM. Does doing housework keep you healthy? The contribution of domestic physical activity to meeting current recommendations for health. BMC Public Health. 2013;13(1):966.

19. Smith PJ, Potter GG, McLaren ME, Blumenthal JA. Impact of aerobic exercise on neurobehavioral outcomes. Ment Health Phys Act. 2013;6(3):139-53.

20. Parisi JM, Rebok GW, Seeman TE, Tanner EK, Tan EJ, Fried LP, dkk. Lifestyle activities in sociodemographically at-risk urban, older adults prior to participation in the Baltimore Experience Corps ${ }^{\circledR}$ Trial. Act Adapt Aging. 2012;36(3):242-60.

21. Kim HH. Effects of experience-based group therapy on cognitive and physical functions and psychological symptoms of elderly people with mild dementia. J Phys Ther Sci. 2015;27(7):2069-71.

22. Okahashi S, Seki K, Nagano A, Luo Z, Kojima M, Futaki T. A virtual shopping test for realistic assessment of cognitive function. J Neuroeng Rehabil. 2013;10(1):59.

23. Gold DA. An examination of instrumental activities of daily living assessment in older adults and mild cognitive impairment. J Clin Exp Neuropsychol. 2012;34(1):11-34.

24. Sikkes SA, Rotrou JD. A qualitative review of instrumental activities of daily living in dementia: what's cooking? Neurodegener Dis Manag. 2014;4(5):393-400.

25. Wen X, Liang Y, Zhu J, Wu T. The effects of housework on the health of retired older adults: a preliminary investigation from the Tongji-Dongfeng cohort study, China. PLoS One. 20138(3):e57232. 